\title{
Mental Health Consequences of Pre- and Peri-Military Violence Victimization among United States Army Soldiers: The Moderating Effect of Resilience
}

\author{
Jessica Kelley Morgan*, James Trudeau, Joel K. Cartwright, Pamela K. Lattimore \\ Behavioral Health and Criminal Justice Research Division, RTI International, Research Triangle Park, NC, USA \\ Email: *jemorgan@rti.org
}

How to cite this paper: Morgan, J. K., Trudeau, J., Cartwright, J. K., \& Lattimore, P. K. (2017). Mental Health Consequences of Pre- and Peri-Military Violence Victimization among United States Army Soldiers: The Moderating Effect of Resilience. Psychology, 8, 2428-2445.

https://doi.org/10.4236/psych.2017.814153

Received: October 11, 2017

Accepted: December 15, 2017

Published: December 18, 2017

Copyright $\odot 2017$ by authors and Scientific Research Publishing Inc. This work is licensed under the Creative Commons Attribution International License (CC BY 4.0). http://creativecommons.org/licenses/by/4.0/

\section{Open Access}

\begin{abstract}
Several factors must be considered when examining violence victimization and mental health consequences among military service members: the prevalence of pre-military victimization, the risk of subsequent victimization conferred by prior victimization, the cumulative or multiplicative effect of adverse events, and the prevalence of trauma exposure and mental health issues in the military, as well as protective factors, such as resilience. The present study seeks to examine the differential impact of several types of victimization both pre- and peri-military on current mental health symptoms, as well as the potential buffering effect of resilience, in a sample of United States Army Soldiers $(N=947)$. To address our research aims, we conducted multiple regression analyses to examine associations of violence victimization with PTSD and depression symptoms in separate models, and a simple moderation analysis was performed. Higher ratings of minor forms of victimization in the military, weapon victimization in the military, sexual victimization both pre- and peri-military, being beat up pre-military, and life events were associated with more of PTSD symptoms, while higher levels of resilience were associated with fewer PTSD symptoms. Higher ratings of minor victimization in the military, sexual victimization pre-military, being beat up pre-military, life events, and combat were associated with higher levels of depression symptoms, while resilience was associated with lower ratings of depression symptoms. We found that psychological resilience buffered against the effects of victimization history on current symptoms of both PTSD and depression. Even at low levels of victimization, resilience was protective against PTSD and depressive symptoms. Our results support the deleterious effects of sexual assault victimization while in the military, and highlight the importance of several pre-military
\end{abstract}


forms of victimization as continuing to predict current mental health among service members. Finally, in addition to the prevention of violence in the military, these findings suggest that efforts to increase resilience may be worthwhile.

\section{Keywords}

Victimization, Military, Resilience, PTSD, Depression

\section{Introduction}

In the examination of violence victimization and mental health consequences among military service members, there are several factors that must be considered: the prevalence of pre-military victimization, the risk of subsequent victimization conferred by prior victimization, the cumulative or multiplicative effect of adverse events, and the prevalence of trauma exposure and mental health issues in the military. First, it is well-documented that service members report higher levels of interpersonal victimization pre-military than their civilian counterparts. In one population-based sample, a comparison of men with and without a history of military service in the all-volunteer era (post-1973) a higher prevalence of all eleven categories of adverse childhood experiences was found, with the most marked difference being for sexual abuse (Blosnich, Dichter, Cerulli, Batten, \& Bossarte, 2014). Men with a history of military service were also twice as likely as men without such history to report experiencing adverse events in childhood across four or more categories (Blosnich et al., 2014). A subsequent study extended these findings by assessing gender differences and found that women with a history of military service were more likely to report childhood physical abuse than civilians (23.2 versus 16.2 percent), as well as childhood verbal abuse (41.5 versus 27.4 percent) and childhood sexual abuse (21.2 versus 16.3 percent) (Katon et al., 2015). The differences were less pronounced for men, but still significant across childhood physical, verbal, and sexual abuse (Katon et al., 2015). Results also suggest that military enlistees not only report higher levels of childhood abuse, but also report more exposure to various interpersonal traumas both in adolescence and early adulthood as well (Wolfe et al., 2005). A critical review of trauma among female Veterans found that not only do female Veterans report higher rates of trauma exposure than their civilian counterparts, but that they are subsequently at risk for cumulative trauma exposure (Zinzow, Grubaugh, Monnier, Suffoletta-Maierle, \& Frueh, 2007).

The findings by Zinzow and colleagues (2007) are related to the second factor for consideration. Namely, research has shown that those who are victims of prior violence, such as childhood sexual abuse, are at greater risk for subsequent sexual assault victimization (Merrill et al., 1999). In a sample of female Veterans, those who reported the highest rates of physical and sexual abuse during childhood, and those who had been raped prior to enlisting in the military, also reported the most victimization during the military (Sadler, Booth, Mengeling, \& 
Doebbeling, 2004). Having a history of childhood physical or sexual abuse or being raped prior to enlistment predicted non-fatal physical assault in the military among women Veterans of Vietnam, post-Vietnam, and Persian Gulf War eras as well (Sadler, Booth, Cook, Torner, \& Doebbeling, 2001).

Third, adverse events can have a cumulative or multiplicative effect on mental health. Among National Guard Soldiers returning from Iraq and Afghanistan, for example, prior interpersonal victimization predicted post-deployment PTSD symptoms, even after controlling for baseline symptoms (Polusny et al., 2014). In another study of Soldiers who had deployed to Iraq, both adverse childhood events and combat exposure predicted PTSD symptoms, but there was an interaction effect as well; the relationship between combat and PTSD symptoms was greater for those who had experienced more adverse events in childhood (Cabrera, Hoge, Bliese, Castro, \& Messer, 2007). This finding was supported in a study of United States Marines, in which those with childhood adverse experiences, specifically childhood physical neglect, were more likely to be diagnosed with PTSD following a deployment (Leard Mann, Smith, \& Ryan, 2010). Among Veterans Affairs primary care patients, PTSD and depression were differentially associated with prior trauma by type; men who were diagnosed with PTSD were more likely to be victims of interpersonal violence or report war zone trauma (Freedy et al., 2010). For women, sexual victimization and being a victim of interpersonal violence were associated with PTSD; the same patterns were found for depression (Freedy et al., 2010).

Fourth and finally, extant research has shown that military members experience PTSD at higher rates than their civilian counterparts (Gradus, 2016). It has been estimated that the lifetime prevalence of PTSD among adult Americans is $6.8 \%$ (Kessler, Berglund et al., 2005), and past year prevalence at 3.5\% (Kessler, Chiu, Demler, Merikangas, \& Walters, 2005). Among those serving in Operation Enduring Freedom and Operation Iraqi Freedom, however, prevalence rates of PTSD have been reported at 13.8\% (Tanielian \& Jaycox, 2008). Upon return from a deployment to Iraq or Afghanistan, PTSD rates have been shown to be higher than prior to deployment, which suggests that deployment may be a risk factor for the development of PTSD among military service members (Hoge et al., 2004a).

In addition to the four aforementioned factors (i.e., the prevalence of pre-military victimization, the risk of subsequent victimization conferred by prior victimization, the cumulative or multiplicative effect of adverse events, and the prevalence of trauma exposure and mental health issues in the military), protective factors must be considered as well. There has been a palpable shift in the field of psychology from a narrow focus on the treatment of pathology to the prevention of mental health issues through the promotion of positive skills and resources that may contribute to resilience (Peterson \& Seligman, 2004). Resilience is essentially the ability to "bounce back" or return to one's original state. In psychology, it can be defined as "processes or patterns of positive adaptation 
and development in the context of significant threats to an individual's life or function" (Masten \& Wright, 2010: p. 215). The construct of psychological resilience is believed to be a somewhat stable, though malleable, set of positive coping skills that protect against the development of traumatic stress (Charuvastra \& Cloitre, 2008; Hoge, Terhakopian, Castro, Messer, \& Engel, 2007; King, King, Fairbank, Keane, \& Adams, 1998) and depression (Southwick, Vythilingam, \& Charney, 2005). Resilience has been shown to protect against the development of PTSD following combat in Army Reserve soldiers (Bartone, 1999) and Vietnam Veterans (King et al., 1998; Waysman, Schwarzwald, \& Solomon, 2001). There has been a growing interest in research on resilience in identifying compensatory factors that may have "protective or moderating effects" and a "buffering or ameliorative influence" (Masten \& Wright, 2010: p. 215).

The existing scientific literature on the effects of victimization on mental health in the military is limited in several important ways. First, investigations of types of pre-military violence victimization have been largely restricted to childhood sexual or physical abuse. Second, studies of in-military victimization have focused on these same categories, with the overwhelming majority focusing solely on sexual assault. Third, little research has examined the effects of various trauma types across several timeframes on current mental health symptoms. Fourth, no studies have examined protective factors that may ameliorate such effects. The present study seeks to fill these gaps by examining the differential impact of several types of victimization both pre- and peri-military on current mental health symptoms, as well as the potential buffering effect of resilience, in a sample of United States Army Soldiers.

\section{Methods}

\subsection{Participants and Procedures}

Participants were Active-Duty Army Soldiers $(N=947)$ at a large East coast military installation. Following study approval by the RTI International Institutional Review Board (IRB) and the U.S. Army Medical Research and Materiel Command Office of Research Protections, Soldiers from a sample of operational units were asked to attend an information session about the survey. Participation was voluntary and surveys were anonymous. All volunteers were consented and completed their surveys on individual electronic tablets.

\subsection{Measures}

\subsubsection{Dependent Variables}

Posttraumatic Stress Disorder (PTSD) symptoms. PTSD symptom severity was assessed using the PTSD Checklist, Civilian Version (PCL-C; Weathers, Litz, Herman, Huska, \& Keane, 1994). The checklist is a 17-item questionnaire that asks respondents to rate the extent to which they have been bothered by PTSD symptoms during the previous 30 days. The scale has good sensitivity and specificity (Lang, Laffaye, Satz, Dresselhaus, \& Stein, 2003; Weathers et al., 1994), is 
considered a valid and reliable screening instrument (Keen, Kutter, Niles, \& Krinsley, 2008; Ruggiero, Del Ben, Scotti, \& Rabalais, 2003), and has been widely used in military studies (Bliese et al., 2008; Dobie et al., 2002). The civilian version (PCL-C) was used rather than the military version (PCL-M) to capture PTSD symptoms resulting from nonmilitary traumatic experiences as well as deployment-related exacerbations of PTSD symptoms, if the original inciting trauma was not military-related. Respondents rated items using a 5-point scale ranging from "not at all" to "extremely" and ratings were summed for a total score of $17=85$. Scale scores showed excellent reliability in this sample (Cronbach's $\alpha=.97$ ).

Depression symptoms. Depression symptoms were assessed with the 9-item depression module from the Patient Health Questionnaire (PHQ) known as the PHQ-9 (Kroenke, Spitzer, \& Williams, 2001). The PHQ-9 scores each of the 9 DSM-IV criteria as 0 ("not at all") to 3 ("nearly every day") which are summed to yield a total score ranging from 0 to 27 with scores of $5,10,15$, and 20 representing mild, moderate, moderately severe, and severe depression symptoms. PHQ-9 scores $\geq 10$ have shown a sensitivity of $88 \%$ and specificity of $88 \%$ for major depression (Kroenke et al., 2001). PHQ-9 scores showed excellent internal reliability in this sample (Cronbach's $\alpha=.95$ ).

\subsubsection{Predictor Variables}

Prior violence victimization. Respondents reported whether they had experienced nine different violence victimization items, and also marked whether the event happened "more than 12 months ago, but during military service" or "prior to military service". Factor analysis revealed that the nine items reflected four different types of violence. Minor victimization included being pushed, grabbed, shoved, slapped, or kicked, among others, and resulted in a score of 0 4. Being beat up emerged as its own factor and included being hit with a fist or object $(0=$ no, yes $=1)$. Weapon victimization included being threatened with or being attacked with a knife, gun or lethal weapon and resulted in a 0 - 2 score. Sexual victimization included unwanted touching and attempted or completed rape and was also coded $0-2$. For inclusion in the interaction term, we also created a sum score of cumulative victimization history.

Resilience. The brief resilience scale (BRS Smith et al., 2008) was used to assess the ability to bounce back or recover from stress. The BRS consists of six items about how the respondent tends to deal with stress; it is measured on a 5-point scale of "strongly disagree" to "strongly agree" with higher scores reflecting higher levels of resilience. BRS scale scores showed good reliability in this sample (Cronbach's $\alpha=.80$ ).

\subsubsection{Control Variables}

Demographics. We controlled for several demographic characteristics, including age, marital status (dichotomized as married or living as married $=0$, and not married and not living as married $=1)$, gender $($ female $=0$, male $=1$ ), and 
enlisted status (enlisted $=0$, officer $=1$ ).

Combat exposure. Exposure to combat was measured using a 17-item scale adapted for the Department of Defense Survey of Health Related Behaviors (Bray et al., 2009), from the Deployment Risk and Resilience Inventory (Vogt et al., 2013; Vogt, Proctor, King, King, \& Vasterling, 2008), and the Land Combat study (Hoge et al., 2004b). Items assess exposure to incoming fire, mines, and improvised explosive devices, as well as commonly experienced combat situations such as firing on the enemy, viewing dead bodies or human remains, and interacting with enemy prisoners of war. Each item asks how many times the respondent has been exposed with 5 categorical response options ranging from 0 (0 times) to 4 (51 or more times) over all deployments. All items were summed, and the sum score was used to create a categorical combat exposure item where a score equal to zero was considered "No Exposure", a score from 1 to 9 was considered "Moderate Exposure", and a score of 10 or greater was considered "High Exposure". In this sample, combat scores were substantially intercorrelated with excellent internal consistency (Cronbach's alpha =.92).

Prior life events. Prior life events and stressors were assessed using a modified version of the predeployment life events/prior stressors module of the Deployment Risk and Resilience Inventory-2 (DRRI-2; Vogt, Smith, King, \& King, 2012), which assessed stressful or traumatic events such as "someone close to me died". In order to prevent issues of multicollinearity, we removed violence victimization items, such as those asking about prior sexual assault. A sum score was created to measure cumulative exposure to stressful life events.

\subsection{Statistical Analysis}

All analyses were run using SAS version 9.4 software (SAS Institute Inc, Cary, NC). Prior to addressing our research aims, we computed univariate statistics to describe the sample and ran bivariate analyses to identify possible issues with multicollinearity. To address our research aims, multiple regression analyses were conducted using PROC SURVEYREG to examine associations of violence victimization with PTSD and depression symptoms in separate models. Next, a simple moderation analysis was performed using the Hayes PROCESS macro for mediation, moderation, and conditional process analyses, specifically Hayes' Model 1 (Hayes, 2013). See Hayes (2013) for the statistical model and equation of this simple moderation model. Predictor variables were mean centered prior to analysis. Conditional effects (i.e., simple slopes) were then calculated with all covariates set to their sample means. Simple slopes were tested for low $(-1 S D$ below the mean), medium (mean), and high (+1 $S D$ above the mean) levels of resilience.

\section{Results}

\subsection{Descriptive Statistics}

Table 1 shows the descriptive statistics for the participant characteristics and 
Table 1. Sample descriptive statistics.

\begin{tabular}{|c|c|c|}
\hline Variable & $M$ & $S D$ \\
\hline Age & $\begin{array}{c}24.6 \\
n\end{array}$ & $\begin{array}{c}5.3 \\
\text { Percent }\end{array}$ \\
\hline \multicolumn{3}{|l|}{ Sex } \\
\hline Male & 722 & 78.6 \\
\hline Female & 197 & 21.4 \\
\hline \multicolumn{3}{|l|}{ Education } \\
\hline Less than High School & 4 & 0.4 \\
\hline High School Graduate/GED & 448 & 48.8 \\
\hline Trade or Technical School & 28 & 3.1 \\
\hline Some College but No Degree & 269 & 29.3 \\
\hline 2-Year College Degree/Associate's & 74 & 8.1 \\
\hline 4-Year College Degree/Bachelor's & 64 & 7.0 \\
\hline $\begin{array}{l}\text { Post-Graduate Training (Master's Degree, } \\
\text { Ph.D., Law or Medical School) }\end{array}$ & 34 & 3.4 \\
\hline \multicolumn{3}{|l|}{ Race $^{*}$} \\
\hline White & 548 & 60.0 \\
\hline Black or African-American & 259 & 28.4 \\
\hline American Indian or Alaska Native & 36 & 3.9 \\
\hline $\begin{array}{l}\text { Asian (e.g., Asian Indian, Chinese, Filipino, } \\
\text { Japanese, Korean, Vietnamese) }\end{array}$ & 34 & 3.7 \\
\hline Native Hawaiian or Other Pacific Islander & 10 & 1.1 \\
\hline Other & 110 & 12.1 \\
\hline \multicolumn{3}{|l|}{ Spanish/Hispanic/Latino } \\
\hline Yes & 214 & 23.2 \\
\hline No & 709 & 76.8 \\
\hline \multicolumn{3}{|l|}{ Marital Status } \\
\hline Married & 386 & 42.1 \\
\hline Living as married & 56 & 6.1 \\
\hline Divorced & 43 & 4.7 \\
\hline Separated & 41 & 4.5 \\
\hline Widowed & 2 & 0.2 \\
\hline Never been married & 389 & 42.4 \\
\hline \multicolumn{3}{|l|}{ Rank } \\
\hline E1 - E3 & 275 & 29.8 \\
\hline E4 - E6 & 590 & 63.9 \\
\hline E7 - E9 & 19 & 2.1 \\
\hline W1 - W5 & 11 & 1.2 \\
\hline $\mathrm{O} 1-\mathrm{O} 10$ & 28 & 3.0 \\
\hline
\end{tabular}

Notes. $N=913$. ${ }^{\star}$ Participants were asked to mark all that apply. 
variables of interest. The sample averaged 24.58 years old $(S D=5.28)$ and most were E4-E6 rank (63.9\%). Most participants were male (78.6\%) and the vast majority were enlisted (95.8\%). Approximately half of the sample had at least some education beyond high school (50.9\%) and slightly less than half of the sample had only a high school diploma or GED (48.8\%). More than half of the sample was white $(60.0 \%)$, and did not identify as Hispanic or Latino (76.8\%). Additionally, roughly half of participants $(48.2 \%)$ were married or living as married.

\subsection{Bivariate Results}

Bivariate analyses showed relationships among many predictor and outcome variables. In particular, results of correlational analyses, depicted in Table 2, showed that all type and time combinations of violence victimization were positively correlated with one another, with the exception of two. Being a victim of sexual violence while in the military was not associated with being a victim of minor violence or being beat up before entering the military. Prior life stressors were correlated with all forms of victimization as well. Resilience was positively correlated with pre-military weapon victimization and negatively related to being a victim of sexual violence in the military, although both associations were small. Finally, combat exposure was positively correlated with peri-military minor victimization, being beaten up, and weapons victimization, as well as prior life events.

\subsection{Multivariate Results}

Table 3 provides the results of the regression models with victimization, resilience, and life events predicting PTSD and depression symptoms. We included age, sex, and combat as control variables due to prior significant associations

Table 2. Bivariate correlations of continuous predictors, control, and dependent variables.

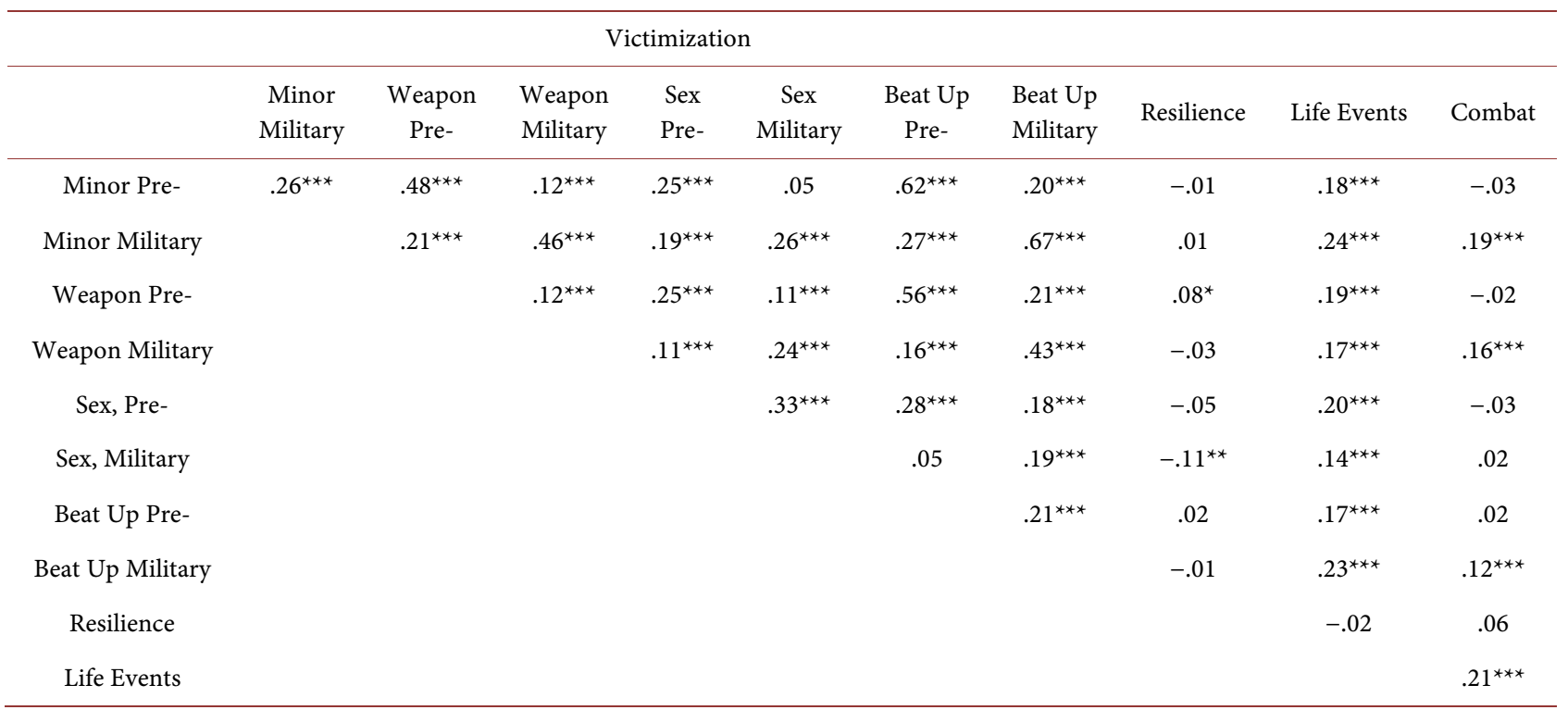

Note. $N=832-881 .{ }^{*} p<.05,{ }^{* *} p<.01,{ }^{* * *} p<.001$. 
with the outcome variables. Overall, the model predicting PTSD symptoms was significant and accounted for $23.1 \%$ of the variance, $F(14,722)=12.29, p<.001$. Minor forms of victimization in the military, weapon victimization in the military, sexual victimization both pre- and peri-military, being beat up pre-military, life events, and resilience emerged as significant predictors (see Table 3 ). Specifically, higher ratings of minor forms of victimization in the military, weapon victimization in the military, sexual victimization both pre- and peri-military, being beat up pre-military, and life events were associated with more of PTSD symptoms, while higher levels of resilience were associated with fewer PTSD symptoms. Pre-military minor victimization was also significant at $p<.10$. The model predicting depressive symptoms was also significant and accounted for $21.6 \%$ of the variance, $F(14,733)=11.60, p<.001$. Minor victimization in the military, sexual victimization pre-military, being beat up pre-military, life events, combat, and resilience emerged as significant predictors. Higher ratings of minor victimization in the military, sexual victimization pre-military, being beat up pre-military, life events, and combat were associated with higher levels of depression symptoms, while resilience was associated with lower ratings of depression symptoms (see Table 3 ).

For both models, the interaction term between resilience and victimization history was also significant, and explained a significant increase in variance in

Table 3. Predictors of depression and PTSD symptoms.

\begin{tabular}{|c|c|c|c|c|c|c|}
\hline \multirow{3}{*}{ Variables } & \multicolumn{6}{|c|}{ Model Statistics } \\
\hline & \multicolumn{3}{|c|}{ PTSD Symptoms } & \multicolumn{3}{|c|}{ Depression Symptoms } \\
\hline & $\beta$ & $S E$ & $p$ & $\beta$ & $S E$ & $p$ \\
\hline Intercept & 44.95 & 3.95 & $<.001$ & 11.55 & 1.74 & $<.001$ \\
\hline Minor, Pre- & 2.19 & 1.12 & 0.051 & 0.71 & 0.43 & 0.101 \\
\hline Minor, Military & 4.36 & 1.53 & 0.004 & 1.67 & 0.57 & 0.003 \\
\hline Weapon, Pre- & 2.99 & 1.83 & 0.102 & 0.87 & 0.68 & 0.203 \\
\hline Weapon, Military & 5.22 & 2.36 & 0.028 & 1.05 & 0.82 & 0.202 \\
\hline Sex, Pre- & 4.89 & 2.07 & 0.019 & 1.31 & 0.67 & 0.049 \\
\hline Sex, Military & 5.92 & 2.66 & 0.026 & 1.49 & 0.96 & 0.122 \\
\hline Beat Up, Pre- & 5.75 & 2.16 & 0.008 & 2.10 & 0.83 & 0.012 \\
\hline Beat Up, Military & 0.93 & 3.43 & 0.787 & -0.71 & 1.21 & 0.555 \\
\hline Resilience & -5.53 & 0.79 & $<.001$ & -2.28 & 0.33 & $<.001$ \\
\hline Life Events & 0.82 & 0.33 & 0.014 & 0.47 & 0.12 & $<.001$ \\
\hline Combat & 0.74 & 0.67 & 0.272 & 0.60 & 0.28 & 0.034 \\
\hline Age & -0.01 & 0.10 & 0.998 & -0.02 & 0.04 & 0.603 \\
\hline Sex & -0.55 & 1.40 & 0.694 & -0.35 & 0.56 & 0.530 \\
\hline Resilience $\mathrm{x}$ Victimization History & -0.72 & 0.27 & 0.007 & -0.24 & 0.10 & 0.019 \\
\hline
\end{tabular}

Note. $N_{\text {PTSD }}=723 . N_{\text {Depression }}=734$. 
$\operatorname{PTSD}\left(\Delta R^{2}=.01, F(1,718)=12.49, p<.001\right)$ and depression $\left(\Delta R^{2}=.01, F(1\right.$, $730)=6.79, p<.001)$. For PTSD, the unstandardized conditional effect for Soldiers $1 S D$ below the mean of resilience was $1.41(p<.001)$. The unstandardized conditional effect for Soldiers with a mean level of resilience was $0.75(p<.001)$, and the unstandardized conditional effect for Soldiers $1 S D$ above the mean of resilience was 0.08 ( $p=.745)$. Figure 1 plots this interaction. For depression, the unstandardized conditional effect for Soldiers $1 S D$ below the mean of resilience was $0.38(p<.001)$. The unstandardized conditional effect for Soldiers with a mean level of resilience was $0.07(p=.011)$, and the unstandardized conditional effect for Soldiers $1 S D$ above the mean of resilience was $-0.01(p=.960)$. Figure 2 plots this interaction.

\section{Discussion}

Of the type and time combinations of violence victimization in this sample of U.S. Army Soldiers, the most robust predictor of PTSD was sexual assault victimization during military service. Reporting being beat up prior to entering the military was the strongest pre-military predictor of PTSD, and resilience emerged as a strong protective factor. For depression, resilience was the most robust predictor out of both the risk and protective factors. Being beat up prior to entering the military was the strongest predictor of increased symptoms of depression, followed by being a victim of minor and sexual forms of violence during military service. Overall, more violence victimization experiences were related to PTSD than to depression.

Our significant moderation results warrant mention. We found that psychological resilience buffered against the effects of victimization history on current

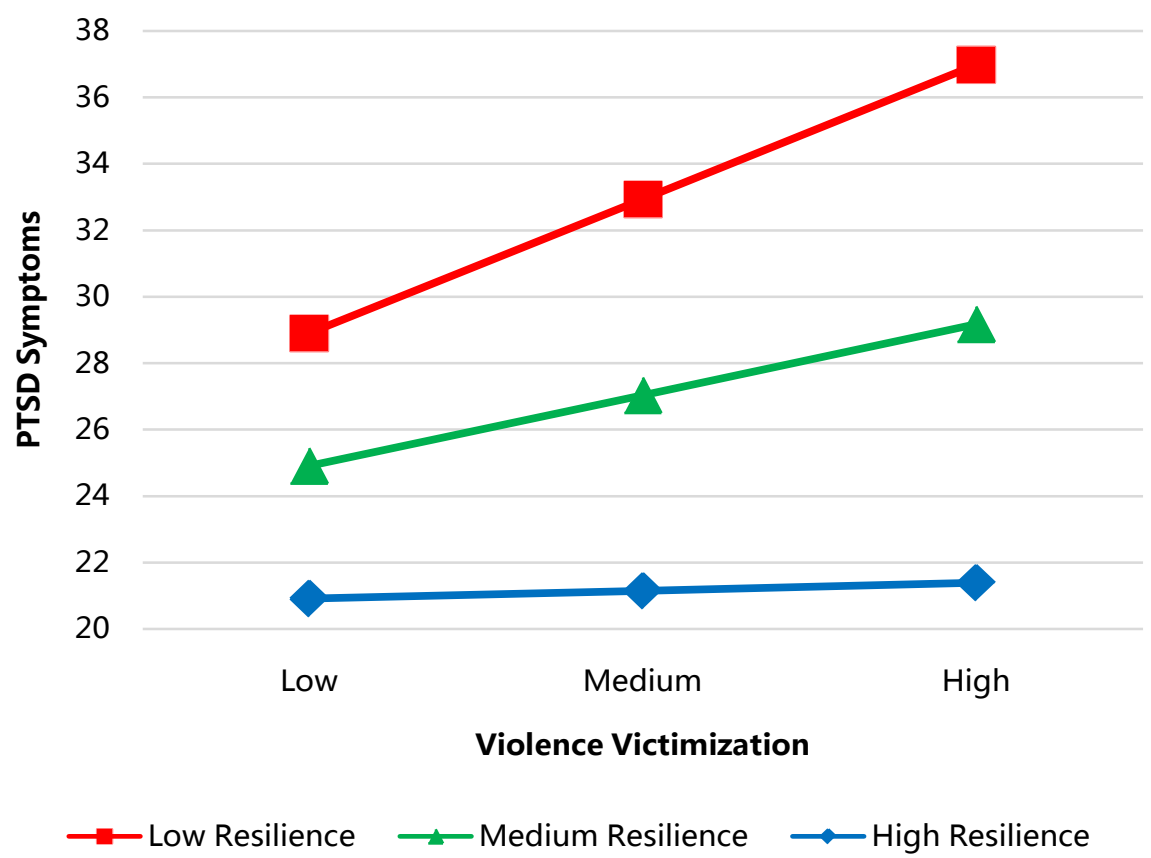

Figure 1. Conditional effects of victimization history on PTSD symptoms by resilience. 


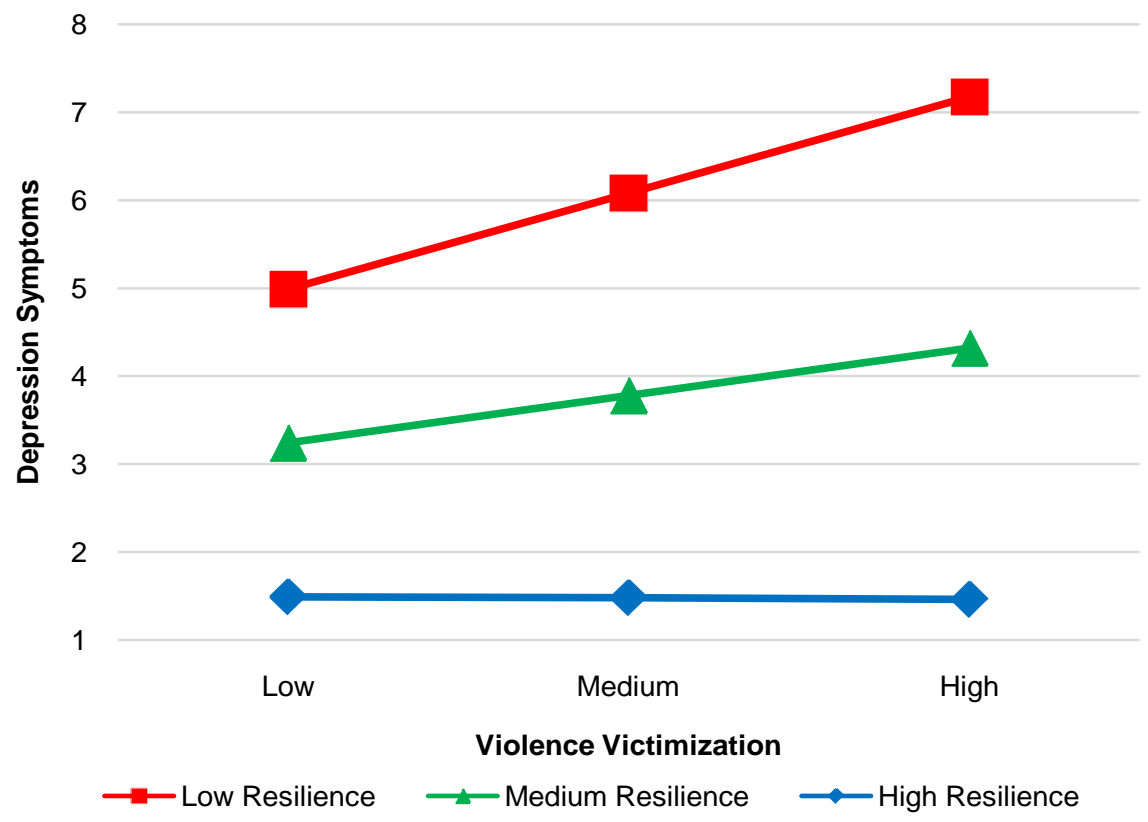

Figure 2. Conditional effects of victimization history on depression symptoms by resilience.

symptoms of both PTSD and depression. Even at low levels of victimization, resilience was protective against PTSD and depressive symptoms; those reporting the highest levels of resilience reported the lowest levels of symptomatology, those reporting the lowest levels of resilience reported the most symptoms, and those reporting average levels of resilience were in between. These significant differences were more pronounced at medium levels of victimization, and most pronounced at the highest levels. The relationship between victimization history and PTSD or depression was strongest for those with lowest resilience and still significant for those with average resilience, but more weakly associated. For those reporting the highest levels of resilience, the association between victimization history and PTSD or depressive symptoms was nonsignificant. This means that for the Soldiers in our sample with average or below average levels of resilience, each additional experience of victimization conferred risk for increases in PTSD and depressive symptoms, but for those with above average levels of resilience, increased victimization did not predict more symptoms.

These findings have implications for research, practice, and policy. First, our results support the deleterious effects of sexual assault victimization while in the military. Most survivors of sexual assault during military service report that the perpetrator was also in the military (Morral et al., 2016; Sexual Assault Prevention and Response Office, 2016). Because there is a sort of implicit trust afforded to fellow service members and a culture of family (Ashley, Counts et al., 2017; Morgan, Ashley, Hill, Relyea, \& Charm, 2017), this experience of victimization may be qualitatively different than other forms of violence. This type of violence may be seen as a betrayal, and subsequently be more likely to challenge one's core beliefs about the world (Cann et al., 2010; Morgan, Desmarais, Mitchell, \& 
Simons-Rudolph, 2017) or shatter fundamental assumptions (Cann, Calhoun, Addington, \& Groleau, 2013; Janoff-Bulman, 1992). Sexual assault in the military has consequences beyond the negative effects on the mental health of the victim, including damage to morale, trust, and unit cohesion; mission degradation; and decreased readiness and retention (Ashley, Morgan et al., 2017; Stimson, 2013). Continued efforts should be made to prevent sexual assault in the military and increase reporting, particularly among male victims (Sexual Assault Prevention and Response Office, 2016; U.S. Government Accountability Office (GAO), 2015).

Second, this study highlights the importance of several pre-military forms of victimization as continuing to predict current mental health among service members. In particular, being beat up or sexually abused prior to entering the military were still predictive of PTSD and depression symptoms, even after accounting for other forms violence, combat, and traumatic life events. Again, there are consequences beyond individual-level mental health. Some forms of premilitary victimization, such as intimate partner violence and rape, have been associated with increased likelihood of attrition from the military (Merrill, Stander, Thomsen, Crouch, \& Milner, 2006; Stander, Merrill, Thomsen, Crouch, \& Milner, 2007), and this association may be particularly strong for female recruits (Wolfe et al., 2005). Understanding that people enter service with previous trauma is necessary to develop programs aimed at coping skills early on in one's military career, before the recruit is likely exposed to additional adverse events common to military life.

Third, our findings elucidate the need for a holistic approach to understanding mental health. Specifically, both risk and protective factors should be considered when assessing or treating mental health concerns following victimization, or other types of trauma, more generally. Resilience, in this case, remained a significant protective factor, outweighing the predictive capability of many forms of victimization and trauma for PTSD, and most strongly for depression. More importantly, we found a buffering effect of resilience on the mental health consequences of victimization. These results suggest that, in addition to the prevention of violence in the military, efforts to increase resilience may be worthwhile. Efforts have been made in the military to develop resilience trainings, such as Comprehensive Soldier Fitness (Casey, 2011; Cornum, Matthews, \& Seligman, 2011), now Comprehensive Soldier and Family Fitness (CSF2), and evaluations of these efforts have been promising (Harms, Herian, Krasikova, Vanhove, \& Lester, 2013). Still, budget concerns continue to threaten efforts to improve, evaluate, and implement resilience training in the military (Dunning II, 2013). Additionally, if leaders in the military community undervalue the importance of resilience training, and therefore fail to implement these programs with fidelity, the efforts will be futile (Sims \& Adler, 2017). Our findings demonstrate a need for policies that support continued funding and human resources to develop, rigorously evaluate, and implement programs aimed at enhancing resilience in 
the military.

\section{Limitations and Future Directions}

When considering the implications of our findings, limitations of the study design should be considered. First, the cross-sectional and correlational nature of this study precludes inferences of causality, or a thorough understanding of the temporal nature of resilience. To address this issue to the extent possible, we examined current mental health symptoms as a function of victimization that happened at least one year prior, in order to account for issues of temporality. Still, future studies should examine whether pre-trauma resilience is particularly protective, or if post-trauma facilitation of resilience is able to confer the same benefits. Second, our measures of resilience, victimization history, and current mental health symptoms were assessed through self-report, which may be biased by social desirability. However, in situations where the respondent is not being evaluated, as was the case in this study, research suggests that social desirability may not be as strong as was once believed (Chan, 2009). Third, our measure of psychological resilience (i.e., the Brief Resilience Scale; Smith et al., 2008) may be assessing a narrow definition of resilience. Future research should examine the effects of resilience trainings on related constructs, such as hardiness, optimism, and grit, to determine the construct being targeted. Finally, given the limited number of females in our sample, we were unable to explore if gender differentially impacted each association or examine three-way interactions. This study focused on previously unexamined main effects, as well as the moderating effect of resilience on these relationships. Larger sample sizes that allow for testing moderated moderation are warranted.

\section{Conclusion}

These limitations notwithstanding, this study provides the first information regarding the relative importance of several types of violence victimization across different timeframes vis-à-vis current mental health symptomatology in Active Duty military service members. Our findings offer support for current efforts to decrease military sexual assault, as well as teach coping skills to forestall effects of pre-military trauma. Additionally, this study suggests the value of assessing both risk and protective factors for researchers and clinicians alike. Finally, our results provide further empirical evidence of the importance of resilience as a buffer against the consequences of trauma, and as a promising point of intervention in the military community.

\section{Acknowledgements}

This work was supported by grant number W81XWH-12-2-0095 from the U.S. Army Medical Research and Materiel Command The sponsor had no role in study design; in the collection, analysis and interpretation of data; in the writing of the manuscript; or in the decision to submit the article for publication. The 
views expressed in this article are those of the authors and do not necessarily represent the views of the Departments of Department of Defense, Veterans Affairs, or any U.S. government agency.

\section{References}

Ashley, O. S., Counts, J., Charm, S., Morgan, J. K., Hill, J., Relyea, M., \& Tharp, A. (2017). Perceptions of High-Risk Situations for Sexual Assault: Gender Differences in the United States Air Force. Kissimmee, FL: The Military Health System Research Symposium.

Ashley, O. S., Morgan, J. K., Relyea, M., Charm, S., Lane, M. E., \& Street, A. E. (2017). Working with Male Sexual Assault Victims in the Military. The Military Psychologist, 32, 6-10.

Bartone, P. T. (1999). Hardiness Protects against War-Related Stress in Army Reserve Forces. Consulting Psychology Journal: Practice and Research, 51, 72-82. https://doi.org/10.1037/1061-4087.51.2.72

Bliese, P. D., Wright, K. M., Adler, A. B., Cabrera, O., Castro, C. A., \& Hoge, C. W. (2008). Validating the Primary Care Posttraumatic Stress Disorder Screen and the Posttraumatic Stress Disorder Checklist with Soldiers Returning from Combat. Journal of Consulting and Clinical Psychology, 76, 272-281. https://doi.org/10.1037/0022-006X.76.2.272

Blosnich, J. R., Dichter, M. E., Cerulli, C., Batten, S. V., \& Bossarte, R. M. (2014). Disparities in Adverse Childhood Experiences among Individuals with a History of Military Service. JAMA Psychiatry, 71, 1041-1048.

https://doi.org/10.1001/jamapsychiatry.2014.724

Bray, R. M., Pemberton, M. R., Hourani, L. L., Witt, M., Olmsted, K. L., Brown, J. M., \& Scheffler, S. (2009). Department of Defense Survey of Health Related Behaviors among Active Duty Military Personnel.

Cabrera, O. A., Hoge, C. W., Bliese, P. D., Castro, C. A., \& Messer, S. C. (2007). Childhood Adversity and Combat as Predictors of Depression and Post-Traumatic Stress in Deployed Troops. American Journal of Preventive Medicine, 33, 77-82.

https://doi.org/10.1016/j.amepre.2007.03.019

Cann, A., Calhoun, L. G., Addington, E., \& Groleau, J. (2013). Assumptive Worlds: Shattered or Created by Traumatic Events? Honolulu, Hawai'i: The American Psychological Association Annual Convention.

Cann, A., Calhoun, L. G., Tedeschi, R. G., Kilmer, R. P., Gil-Rivas, V., Vishnevsky, T., \& Danhauer, S. C. (2010). The Core Beliefs Inventory: A Brief Measure of Disruption in the Assumptive World. Anxiety, Stress \& Coping: An International Journal, 23, 19-34. https://doi.org/10.1080/10615800802573013

Casey, G. W. J. (2011). Comprehensive Soldier Fitness: A Vision for Psychological Resilience in the U.S. Army. American Psychologist, 66, 1-3. https://doi.org/10.1037/a0021930

Chan, D. (2009). So Why Ask Me? Are Self-Report Data Really That Bad? In Statistical and Methodological Myths and Urban Legends: Doctrine, Verity and Fable in the Organizational and Social Sciences (pp. 309-336). New York, NY: Routledge/Taylor \& Francis Group.

Charuvastra, A., \& Cloitre, M. (2008). Social Bonds and Posttraumatic Stress Disorder. Annual Review of Psychology, 59, 301-328.

https://doi.org/10.1146/annurev.psych.58.110405.085650 
Cornum, R., Matthews, M. D., \& Seligman, M. E. P. (2011). Comprehensive Soldier Fitness: Building Resilience in a Challenging Institutional Context. American Psychologist, 66, 4. https://doi.org/10.1037/a0021420

Dobie, D. J., Kivlahan, D. R., Maynard, C., Bush, K. R., McFall, M., Epler, A. J., \& Bradley, K. A. (2002). Screening for Post-Traumatic Stress Disorder in Female Veteran's Affairs Patients: Validation of the PTSD Checklist. General Hospital Psychiatry, 24, 367-374. https://doi.org/10.1016/S0163-8343(02)00207-4

Dunning II, R. M. (2013). Sustaining Comprehensive Soldier and Family Fitness: Critical for Army 2020 (Strategy Research Project). Carlisle Barracks, PA: U.S. Army War College. http://www.dtic.mil/docs/citations/ADA589410

Freedy, J. R., Magruder, K. M., Mainous, A. G., Frueh, B. C., Geesey, M. E., \& Carnemolla, M. (2010). Gender Differences in Traumatic Event Exposure and Mental Health among Veteran Primary Care Patients. Military Medicine, 175, 750-758.

https://doi.org/10.7205/MILMED-D-10-00123

Gradus, J. L. (2016). Epidemiology of PTSD. http://www.ptsd.va.gov/professional/PTSD-overview/epidemiological-facts-ptsd.asp

Harms, P. D., Herian, M. N., Krasikova, D. V., Vanhove, A. J., \& Lester, P. B. (2013). The Comprehensive Soldier and Family Fitness Program Evaluation. Report 4: Evaluation of Resilience Training and Mental and Behavioral Health Outcomes. P.D. Harms Publications.

Hayes, A. F. (2013). Introduction to Mediation, Moderation, and Conditional Process Analysis: A Regression-Based Approach. New York: The Guilford Press.

Hoge, C. W., Terhakopian, A., Castro, C. A., Messer, S. C., \& Engel, C. C. (2007). Association of Posttraumatic Stress Disorder with Somatic Symptoms, Health Care Visits, and Absenteeism among Iraq War Veterans. The American Journal of Psychiatry, 164, 150-153. https://doi.org/10.1176/ajp.2007.164.1.150

Hoge, C. W., Castro, C. A., Messer, S. C., McGurk, D., Cotting, D. I., \& Koffman, R. L. (2004). Combat Duty in Iraq and Afghanistan, Mental Health Problems, and Barriers to Care. New England Journal of Medicine, 351, 13-22. https://doi.org/10.1056/NEJMoa040603

Janoff-Bulman, R. (1992). Shattered Assumptions: Towards a New Psychology of Trauma. New York: Free Press.

Katon, J. G., Lehavot, K., Simpson, T. L., Williams, E. C., Barnett, S. B., Grossbard, J. R., Reiber, G. E. et al. (2015). Adverse Childhood Experiences, Military Service, and Adult Health. American Journal of Preventive Medicine, 49, 573-582. https://doi.org/10.1016/j.amepre.2015.03.020

Keen, S. M., Kutter, C. J., Niles, B. L., \& Krinsley, K. E. (2008). Psychometric Properties of PTSD Checklist in Sample of Male Veterans. Journal of Rehabilitation Research and Development, 45, 465-474. https://doi.org/10.1682/JRRD.2007.09.0138

Kessler, R. C., Berglund, P., Demler, O., Jin, R., Merikangas, K. R., \& Walters, E. E. (2005). Lifetime Prevalence and Age-of-Onset Distributions of DSM-IV Disorders in the National Comorbidity Survey Replication. Archives of General Psychiatry, 62, 593-602. https://doi.org/10.1001/archpsyc.62.6.593

Kessler, R. C., Chiu, W. T., Demler, O., Merikangas, K. R., \& Walters, E. E. (2005). Prevalence, Severity, and Comorbidity of 12-Month DSM-IV Disorders in the National Comorbidity Survey Replication. Archives of General Psychiatry, 62, 617-627.

https://doi.org/10.1001/archpsyc.62.6.617

King, L. A., King, D. W., Fairbank, J. A., Keane, T. M., \& Adams, G. A. (1998). Resilience-Recovery Factors in Post-Traumatic Stress Disorder among Female and Male 
Vietnam Veterans: Hardiness, Postwar Social Support, and Additional Stressful Life Events. Journal of Personality and Social Psychology, 74, 420-434.

https://doi.org/10.1037/0022-3514.74.2.420

Kroenke, K., Spitzer, R. L., \& Williams, J. B. (2001). The PHQ-9: Validity of a Brief Depression Severity Measure. Journal of General Internal Medicine, 16, 606-613. https://doi.org/10.1046/j.1525-1497.2001.016009606.x

Lang, A. J., Laffaye, C., Satz, L. E., Dresselhaus, T. R., \& Stein, M. B. (2003). Sensitivity and Specificity of the PTSD Checklist in Detecting PTSD in Female Veterans in Primary Care. Journal of Traumatic Stress, 16, 257-264. https://doi.org/10.1023/A:1023796007788

Leard Mann, C. A., Smith, B., \& Ryan, M. A. (2010). Do Adverse Childhood Experiences Increase the Risk of Postdeployment Posttraumatic Stress Disorder in US Marines? BMC Public Health, 10, 437. https://doi.org/10.1186/1471-2458-10-437

Masten, A. S., \& Wright, M. O. (2010). Resilience over the Lifespan: Developmental Perspectives on Resistance, Recovery, and Transformation. In J. W. Reich, A. J. Zautra, \& J. S. Hall (Eds.), Handbook of Adult Resilience. New York, NY: Guilford Press.

Merrill, L. L., Newell, C. E., Thomsen, C. J., Gold, S. R., Milner, J. S., Koss, M. P., \& Rosswork, S. G. (1999). Childhood Abuse and Sexual Revictimization in a Female Navy Recruit Sample. Journal of Traumatic Stress, 12, 211-225.

https://doi.org/10.1023/A:1024789723779

Merrill, L. L., Stander, V. A., Thomsen, C. J., Crouch, J. L., \& Milner, J. S. (2006). Premilitary Intimate Partner Violence and Attrition from the U.S. Navy. Military Medicine, 171, 1206-1210. https://doi.org/10.7205/MILMED.171.12.1206

Morgan, J. K., Ashley, O. S., Hill, J., Relyea, M., \& Charm, S. (2017). Risky Situations for Male Sexual Assault Victimization in the Military and Strategies for Prevention: The Role of Qualitative Interviews in Formative Research. Presented at the Society for Prevention Research 25th Annual Meeting, Washington DC.

Morgan, J. K., Desmarais, S. L., Mitchell, R. E., \& Simons-Rudolph, J. M. (2017). Posttraumatic Stress, Posttraumatic Growth, and Satisfaction with Life in Military Veterans. Military Psychology, 29, 434-447. https://doi.org/10.1037/mil0000182

Morral, A. R., Gore, K. L., Schell, T. L., Bicksler, B., Farris, C., Ghosh-Dastidar, M., Williams, K. M. et al. (2016). Sexual Assault and Sexual Harassment in the U.S. Military: Volume 2. Estimates for Department of Defense Service Members from the 2014 RAND Military Workplace Study (No. RR-870/2-1-OSD). Santa Monica, CA: RAND Corporation. https://www.rand.org/pubs/research_reports/RR870z2-1.html

Peterson, C., \& Seligman, M. E. P. (2004). Character Strengths and Virtues: A Handbook and Classification. American Psychological Association.

Polusny, M. A., Kumpula, M. J., Meis, L. A., Erbes, C. R., Arbisi, P. A., Murdoch, M., Johnson, A. K. et al. (2014). Gender Differences in the Effects of Deployment-Related Stressors and Pre-Deployment Risk Factors on the Development of PTSD Symptoms in National Guard Soldiers Deployed to Iraq and Afghanistan. Journal of Psychiatric Research, 49, 1-9. https://doi.org/10.1016/j.jpsychires.2013.09.016

Ruggiero, K. J., Del Ben, K., Scotti, J. R., \& Rabalais, A. E. (2003). Psychometric Properties of the PTSD Checklist-Civilian Version. Journal of Traumatic Stress, 16, 495-502. https://doi.org/10.1023/A:1025714729117

Sadler, A. G., Booth, B. M., Cook, B. L., Torner, J. C., \& Doebbeling, B. N. (2001). The Military Environment: Risk Factors for Women's Non-Fatal Assaults. Journal of Occupational and Environmental Medicine, 43, 325-334.

https://doi.org/10.1097/00043764-200104000-00007 
Sadler, A. G., Booth, B. M., Mengeling, M. A., \& Doebbeling, B. N. (2004). Life Span and Repeated Violence against Women during Military Service: Effects on Health Status and Outpatient Utilization. Journal of Women's Health, 13, 799-811.

https://doi.org/10.1089/jwh.2004.13.799

Sexual Assault Prevention and Response Office (2016). Department of Defense Annual Report on Sexual Assault in the Military: Fiscal Year 2015. Washington DC: Department of Defense.

Sims, D. A. II, \& Adler, A. B. (2017). Enhancing Resilience in an Operational Unit. Parameters; Carlisle Barracks, 47, 83-91.

Smith, B. W., Dalen, J., Wiggins, K., Tooley, E., Christopher, P., \& Bernard, J. (2008). The Brief Resilience Scale: Assessing the Ability to Bounce Back. International Journal of Behavioral Medicine, 15, 194-200. https://doi.org/10.1080/10705500802222972

Southwick, S. M., Vythilingam, M., \& Charney, D. S. (2005). The Psychobiology of Depression and Resilience to Stress: Implications for Prevention and Treatment. Annual Review of Clinical Psychology, 1, 255-291.

https://doi.org/10.1146/annurev.clinpsy.1.102803.143948

Stander, V. A., Merrill, L. L., Thomsen, C. J., Crouch, J. L., \& Milner, J. S. (2007). Premilitary Sexual Assault and Attrition in the U.S. Navy. Military Medicine, 172, 254-258. https://doi.org/10.7205/MILMED.172.3.254

Stimson, C. (2013). Sexual Assault in the Military: Understanding the Problem and How to Fix It (Special Report 149 on National Security and Defense). Washington DC: The Heritage Foundation.

http://www.heritage.org/research/reports/2013/11/sexual-assault-in-the-military-under standing-the-problem-and-how-to-fix-it

Tanielian, T., \& Jaycox, L. H. (2008). Invisible Wounds of War: Psychological and Cognitive Injuries, Their Consequences, and Services to Assist Recovery. RAND Corporation.

U.S. Government Accountability Office (GAO) (2015). Military Personnel Actions Needed to Address Sexual Assaults of Male Service Members (No. GAO-15-284). Washington DC.

Vogt, D. S., Proctor, S. P., King, D. W., King, L. A., \& Vasterling, J. J. (2008). Validation of Scales from the Deployment Risk and Resilience Inventory in a Sample of Operation Iraqi Freedom Veterans. Assessment, 15, 391-403. https://doi.org/10.1177/1073191108316030

Vogt, D., Smith, B. N., King, D. W., \& King, L. A. (2012). Manual for the Deployment Risk and Resilience Inventory-2 (DRRI-2): A Collection of Measures for Studying Deployment-Related Experiences of Military Veterans. Boston, MA: National Center for PTSD.

Vogt, D., Smith, B. N., King, L. A., King, D. W., Knight, J., \& Vasterling, J. J. (2013). Deployment Risk and Resilience Inventory-2 (DRRI-2): An Updated Tool for Assessing Psychosocial Risk and Resilience Factors among Service Members and Veterans. Journal of Traumatic Stress, 26, 710-717. https://doi.org/10.1002/jts.21868

Waysman, M., Schwarzwald, J., \& Solomon, Z. (2001). Hardiness: An Examination of Its Relationship with Positive and Negative Long Term Changes Following Trauma. Journal of Traumatic Stress, 14, 531-548. https://doi.org/10.1023/A:1011112723704

Weathers, F. W., Litz, B. T., Herman, D., Huska, J., \& Keane, T. M. (1994). The PTSD Checklist-Civilian Version (PCL-C). Boston, MA: National Center for PTSD.

Wolfe, J., Turner, K., Caulfield, M., Newton, T. L., Melia, K., Martin, J., \& Goldstein, J. (2005). Gender and Trauma as Predictors of Military Attrition: A Study of Marine 
Corps Recruits. Military Medicine, 170, 1037-1043.

https://doi.org/10.7205/MILMED.170.12.1037

Zinzow, H. M., Grubaugh, A. L., Monnier, J., Suffoletta-Maierle, S., \& Frueh, B. C. (2007). Trauma among Female Veterans: A Critical Review. Trauma, Violence \& Abuse, 8, 384-400. https://doi.org/10.1177/1524838007307295 